\title{
A TOSSE DOS IECAS É REALMENTE UM FATOR LIMITANTE
}

\author{
ACE COUGH IS REALLY A LIMITING FACTOR
}

Lucélia Magalhães ${ }^{1}$

\section{RESUMO}

A hipertensão é um problema de saúde pública no Brasil e no mundo. Seu tratamento é fundamental para reduzir lesões em órgãos alvos incluindo o sistema arterial. Assim uma das principais classes terapêuticas são os fármacos que atuam no importante sistema de controle hemodinâmico e metabólico como o sistema renina-angiotensina-aldosterona. Dentre estas classes, os inibidores da enzima conversora da angiotensina (IECAs) tem um papel predominante por ser o primeiro a ser utilizado, acessível e com estudos robustos na diminuição da morbimortalidade. Apesar destas grandes vantagens existe como principal efeito adverso a tosse. Embora não acarrete riscos pode ser bastante desagradável. Afastado outras causas bem comuns de tosse e ela sendo incomodativa deve-se substituir esta família por outra classe terapêutica cuja tosse não tenha sido descrita como um efeito adverso.

Descritores: Inibidores da Enzima Conversora de Angiotensina; Tosse; Hipertensão.

\section{ABSTRACT}

Hypertension is a public health problem in Brazil and worldwide. Its treatment is essential to reduce damage to target organs including the arterial system. Thus, one of the main therapeutic classes are drugs that act in the important hemodynamic and metabolic control system, such as the renin-angiotensin-aldosterone system. Among these classes, angiotensin-converting enzyme inhibitors (ACE inhibitors) have a predominant role as they are the first to be used, accessible and with robust studies in reducing morbidity and mortality. Despite these great advantages, cough is the main adverse effect. Although it does not carry risks, it can be quite unpleasant. Apart from other very common causes of cough and being uncomfortable, this class should be replaced by another whose cough has not been described as an adverse effect.

Keywords: Angiotensin-Converting Enzyme Inhibitors; Cough; Hypertension.

\section{INTRODUÇÃO}

Hipertensão arterial sistêmica (HAS) é uma condição que apresenta níveis pressóricos continuadamente elevados, produzindo de forma consistente lesões das artérias de grande, médio e pequeno calibre, bem como lesões no coração de diversas formas e de outros órgãos nobres como cérebro e rins. Estes órgãos recebem o maior fluxo sanguíneo vindo do coração. Além destas alterações físicas de remodelamento, hipertrofia vascular e miocárdica, existe o desgaste de cisalhamento em todo o território arterial.

Também a HAS vem acompanhada frequentemente de alterações metabólicas importantes, podendo ser agravadas pelos fatores de risco (FR) agregados como: dislipidemia, obesidade global e visceral, tabagismo, estresse psicoemocional, diabetes mellitus (DM) e sedentarismo.

A HAS se associa de forma robusta, independente e consistente com eventos como morte súbita (MS), acidente vascular encefálico (AVE), infarto agudo do miocárdio (IAM), insuficiência cardíaca (IC), doença arterial periférica obstrutiva (DApO) e doença renal crônica (DRC).
Esta condição é um dos mais importantes problemas de saúde pública da atualidade. Representa também um fator de risco independente para todas as manifestações clínicas da aterosclerose, arterioesclerose e todas as doenças cardiovasculares (DCV). Seus custos médicos e socioeconômicos são elevados principalmente devido a suas principais complicações descritas acima ${ }^{1}$

\section{TRATAMENTO DA HAS}

O tratamento da hipertensão arterial visa, como objetivo final, a redução destas alterações citadas. As medicações disponíveis podem alcançar estes objetivos com as reduções das cifras tensionais, os tratamento dos fatores de risco, suas morbidades associadas, bem como, o tratamento das alterações subclínicas. Todas estas abordagens levam a redução do adoecimento e morte causada pela HAS.

Os médicos têm ao seu dispor, no momento, nove grandes grupos de medicações anti-hipertensivas, agrupadas por mecanismos de ações semelhantes, conhecidas como

1. Faculdades de Medicina, UnesulBahia, Bahia, Brasil.

Correspondência: luceliamagalhaes@terra.com.br

http://dx.doi.org/10.47870/1519-7522/2020270392-97 
classes, a saber: os diuréticos, os agentes de ação central, os alfabloqueadores, betabloqueadores, vasodilatadores diretos, bloqueadores dos canais de cálcio (BCC), bloqueadores direto de renina (BDR), bloqueadores dos receptores AT1 da angiotensina II (BRA), e os inibidores da enzima conversora da angiotensina (IECA).

Além da eficácia comprovada, as medicações devem ser seguras para não aumentar os riscos, custos desnecessários e danos aos pacientes com seu uso.

Primum non nocere ou primum nil nocere é um termo latino da bioética que significa "primeiro, não prejudicar". Este conceito se enquadra na prevenção quartenária, conhecida como iatrogenia (evitar danos pela ação do médico ou profissional de saúde no exercício da sua atuação profissional).

O tema deste artigo diz respeito a reação adversa, ou seja o que ocorre com nossa prescrição que não queríamos, por ser prejudicial ou indesejável. No caso em questão é a tosse com o uso de uma classe de anti-hipertensivos: os Inibidores da Enzima Conversora da Angiotensina (IECAs).

Em uma extensa revisão sistemática de meta-analises de 2001, Ross et al. ${ }^{2}$ mostraram em 150 estudos padronizados, englobando 28.922 pacientes hipertensos, (23,2\% com IECAs), que a descontinuação dos remédios pela suas diferentes classes variaram de $6,7 \%$ com os BCC até os menores valores de $3,1 \%$ com os IECAS, mostrando ser um grupo de medicações, além de eficazes, seguras e com descontinuidade baixa.

Assim, os IECAs serão o objeto neste capítulo e sua associação com a tosse. Os IECAs têm como principal mecanismo de ação a inibição da transformação da angiotensina I em angiotensina II (Angio II) pelo bloqueio da convertase, a enzima convertora, alvo dos IECAs. Esta ação leva a queda das cifras tensionais pela redução desta importante substância: a Angio II.

Para entendermos melhor este mecanismo é preciso explicar um pouco o Sistema Renina Angiotensina (SRA) na qual os IECAs prioritariamente atuam. Embora seja o sistema bem complexo, sistêmico, celular e tissular e interligados a outros sistemas, substratos e outros hormônios, como por exemplo a aldosterona, para o nosso propósito, simplificaremos bastante. O Sistema Renina Angiotensina exerce um papel muito importante na homeostase cardiovascular, desempenhando uma função primordial no controle dinâmico da volemia e da resistência vascular periférica. O SRA representa um alvo importantíssimo no tratamento da hipertensão arterial humana. ${ }^{3}$

\section{IECAS}

O primeiro fármaco desta classe foi a salarazina na década de 70, porém tinha meia vida curta e só estava disponível por via venosa. Nos fins da década de 70 surgiu o captopril que tinha meia vida bem mais longa e estava disponível por via oral. Logo depois surgiu o enalapril e por último com formulação modificada, o perindopril. Temos cerca de 10 diferentes IECAs que são comercializadas no Brasil. Embora o perindopril erbumina esteja no mercado desde 1990, só em 2006 foi lançado o perindopril com o novo sal arginina que seria mais estável e com menos efeitos colaterais. Seria portanto a última versão dos IECAs. ${ }^{4}$

Os IECAs são largamente empregados e úteis no tratamento da HAS e da IC, atuam na diminuição de eventos coronarianos após infarto do miocárdio, na doença coronária estável e é um tratamento eficiente em pacientes diabéticos pela diminuição da pressão intraglomerular. Este mecanismo leva a preservação renal pela diminuição da pressão neste sitio renal. ${ }^{4}$

Para exercer sua atividade biológica, a ANG II liga-se, preferencialmente, ao receptor de alta afinidade AT1 existente em uma variedade de tecidos. Assim, o SRA contribui para manter o controle regular da PA entre outras ações. A ANG II vai exercer sua ação nos receptores AT1 onde ocorre a vasoconstrição e atua também no AT2, receptor responsável pela vasodilatação. Uma ativação do SRA provoca uma vasoconstrição sistêmica e uma estimulação do Sistema Nervoso Simpático (SNS), levando

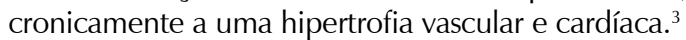

É considerada uma classe segura com poucas reações adversas. Não altera o perfil lipídico, nem metabólico e é considerado uma classe essencial em reduzir mortalidade em IC e pós infarto com dano miocárdico. ${ }^{4}$

\section{TOSSE}

A tosse é o efeito adverso mais comum com o uso dos IECAs e tem uma classificação como problema não fisiológico do uso destas medicações por não estar diretamente relacionada ao bloqueio da ANGIOII. Na imensa maioria dos casos não implica em risco, porém pode ser bastante desagradável.

Ela ocorre habitualmente a noite, logo ao deitar podendo ser confundido com sinusite/rinite (gotejamento da fossa nasal posterior) ou pode despertar o paciente durante o sono. Pode também ocorrer pela manhã e pode ser tão intensa que provoca vômito. ${ }^{5}$ Em contraste, pode ocorrer leve coceira na garganta tipo pigarro e que passa anos completamente desapercebida pelo paciente

O primeiro artigo relatando tosse associada ao captopril foi em 1987 por Coulter et al., ${ }^{6}$ desde então, foram inúmeros estudos de quase todos os tipos de IECAs associando seu uso a presença da tosse.

A tosse é uma queixa muito comum na população como um todo, ocorre com um reflexo fisiológico quase diário. Muitas vezes existe dificuldade do médico e do paciente fazerem esta associação. Geralmente é do tipo seca, não produtiva, irritativa curta e frequente, pode ser relatada espontaneamente ou aparecer no interrogatório sistêmico por ser pouco incomodativa.

Do estudo de Coulter até 1989 na revisão de Strocchi et al. ${ }^{7}$ a sua prevalência variou de $0,2 \%$ a pouco mais de $10 \%$. Nesta época só existia para análise o captopril e o enalapril.

Três anos depois, os IECAs se tornaram uma das classes mais prescritas na clínica médica e em suas subespecialidades. Sendo muito consumida em todo o mundo. Neste ínterim surgiram outros IECAs como benazepril, cilazapril, lisinopril, ramipril, e quinapril e perindopril.

Em uma extensa revisão sobre tosse e IECA Israeli et al. ${ }^{8}$ apresentaram aspectos da fisiopatologia da tosse como o uso de IECAs de todos desta classe, bem como estudos de prevalência com diferentes desenhos, populações e amostras. Nesta revisão houveram 77 estudos com captopril, e ou enalapril, 7 estudos como lisinopril, 3 como ramipril, 2 com quinapril e com os restantes 1 artigo para cada. Mostrando os mesmos achados em relação a frequência de tosse. 
Esta tosse pode se apresentar na primeira semana de uso, porém pode somente se manifestar com até seis meses da introdução desta classe. Em geral desaparece em até quatro dias da sua retirada, porém artigos referem quatro semanas para cessação da mesma. ${ }^{8}$

A prevalência da tosse variou no estudo de Rumbolt et al. ${ }^{9}$ de $0 \%$ até $90 \%$ no estudo de Lacouciére et al. ${ }^{10}$ ambos estudos com captopril e enalapril. Na maioria dos estudos a substituição de um IECAs por outro IECAs não resolveu a tosse. Em dois estudos com enalapril e outro com lisinopril quando trocados por captopril a tosse não retornou. ${ }^{11,12} \mathrm{~A}$ tosse pelo uso dos IECAs não leva à disfunção pulmonar. A espirometria se encontra normal. Para asmáticos, pacientes com doença pulmonar crônica e tabagistas não existe contraindicação à sua prescrição. Não existe diferença se o uso foi para diferentes tipos de hipertensão ou outras indicações para o uso dos IECAs.

Alguns estudos sugerem que os IECAs de longa duração parecem ter maior chance de tosse porém não confirmado por outros. ${ }^{5}$ Dois estudos mostraram que reduzir a dose pode aliviar a tosse..$^{12,13}$

Devemos ficar atentos para outras causas muito comuns de tosse como alergias, doença do refluxo gastroesofágico, bronquite crônica, insuficiência cardíaca, resfriados comuns, rinites e tosse de causa emocional.

Se os médicos falham no reconhecimento de que a tosse pode estar associado ao uso de IECAs, o paciente pode ser submetido a avaliações extensas e desnecessárias. O uso de antitussígeno, bronco dilatadores e antibióticos podem ser custosos e perigosos.

\section{Mecanismos da tosse}

Tosse é um mecanismo reflexo mediato pelo nervo vago. Seu estímulo pode ser por modificação do fluido da árvore respiratória, inalação de certos fluidos e ou partículas.

Em relação a tosse com o uso dos IECAs, vários mecanismos têm sido propostos, porém nenhum foi completamente elucidativo.

A explicação mais consistente tem sido que as bradicininas, normalmente degradadas em parte pela enzima de conversão da angiotensina (ECA) e com o bloqueio dos IECAs existe acúmulo desta substância nos pulmões, como resultado da inibição da Angio II, o que produziria inflamação e bronco constrição. $\mathrm{O}$ acúmulo de bradicinina contribuiria para a irritação da via aérea e tosse em pessoas sensíveis levando a contração da musculatura lisa e edema local. Este mecanismo tem se consolidado, porém estudos controlados com administração de bradicininas de diferentes formas não tem corroborado com esta explicação. Alguns estudos apontam que essa sensibilidade ocorre relacionada à capsaicina, um irritante da árvore brônquica. Pacientes usando captopril têm um limiar muito baixo para produzir tosse com a capsaicina. Outros mecanismos têm sido aventado, como o estímulo exagerado das fibras dos receptores $C$ do trato respiratório elevando a quantidade da substância $\mathrm{P}$, que é um potente broncoconstrictor. Outro mecanismos envolve prostaglandinas. ${ }^{8}$ Atualmente acredita-se que o acúmulo de bradicinina e substância $\mathrm{P}$ em pessoas sensíveis pode ser a explicação mais plausível.

\section{Epidemiologia da tosse}

Em geral os IECAs são bastante utilizados e bem tolerados como já mencionado. Estudos mostram que mulheres asiáticas, negros africanos e não fumantes tem maior prevalência da tosse. ${ }^{4,5,8}$ Estudos mais recentes e mais ampliados em termos de população e acompanhamento, bem como duplo cego, dão conta que a tosse varia de 5 a $10 \% .{ }^{14,15}$

No estudo de Lacourcière et al. ${ }^{10}$ mostraram em pacientes usando lisinopril a mesma foi retirada e reintroduzida em um estudo duplo cego. Neste caso somente $50 \%$ no braço de lisinopril comparado com $29 \%$ no braço do losartana (BRA) apresentaram tosse. Esta classe reconhecida como não produtora de tosse. Daí muitas vezes, a dificuldade de estabelecer relação de causa e efeito com tosse e IECAs.

Um estudo bem desenhado, prospectivo de caso controle comparando duas cidades como Hong Kong (China) e Auckland (Austrália) usou captopril ou enalapril para verificar a incidência de tosse. Foi avaliado por investigadores cegos. A prevalência de tosse entre chineses foi $53 \%$, portanto muito maior que brancos australianos. ${ }^{16}$

Um estudo de $\mathrm{Ng}$ et al. ${ }^{17}$ avaliou a incidência de descontinuação do uso de IECAs por tosse em um centro de cuidado primário em Singapura. Foi uma revisão sistemática de prontuários e cerca de 424 pacientes $(30,4 \%)$ em dois anos tiveram que interromper o uso de IECAs. Foi mais comum a interrupção entre mulheres e o tempo médio de 4 a 6 meses de uso regular. Esta alta prevalência confirma os dados anteriores de mulheres asiáticas com maior chance de apresentar tosse. O interessante deste estudo foi que $57 \%$ da tosse apareceu tardiamente.

Embora tenha-se a ideia de que todos os IECAs são iguais, existem discretas diferenças entre os mais antigos com os mais recentes como fosinopril de 1992, derivado do ácido fosfínico e a nova formulação galênica do perindopril arginina em 2001 no lugar do erbumina de 1990.

Alguns artigos com número limitados de pacientes para o fosinopril com estudo de desenho aberto incluindo relato de casos dão conta de menos tosse com fosinopril ${ }^{18,19} \mathrm{com}$ o peridopril arginina os estudos foram mais robustos e com bastante pacientes alocados $\mathrm{s}^{20-22}$ mostraram menor prevalência de tosse, $3 \%$ em média.

\section{Manejo de pacientes com tosse induzida por IECAs}

Vale ressaltar que tosse é um sintoma muito comum na população geral e às vezes difícil de relacionar como o uso de alguma medicação em particular. Algumas dicas podem ser úteis.Tosse em pacientes sem história familiar de atopia, tabagismo ou infecção respiratória e que está em uso de IECAs deve ser suspeitado como efeito colateral. Deve-se ser suspenso por 10 dias, antes de outras investigações. Caso não ocorra a redução importante ou o desaparecimento da mesma é provavel não ser dos IECAs, embora em poucos casos pode durar por 30 dias. Tentar trocar, para os hipertensos, por outras classes de medicações ou aumentar a dose das demais medicações em uso especialmente na IC.

Esta tosse não responde aos antitussígenos e, às vezes em casos mais leves, reduzir a dose e administrar IECAs de curta duração pode ser útil. Tentar os IECAs mais novos em caso de grande necessidade de seu uso. 
Anti-inflamatórios não esteroides embora possam cessar ou reduzir a tosse não devem ser prescritos por expor o paciente a efeitos adversos mais indesejaveis que a própria tosse.

Para decisão da suspensão ou não da medicação deve ser explicada a relação com a tosse e a decisão pode ser do paciente. Em pacientes com importante disfunção ventricular deve-se esclarecer dos riscos e muitas vezes a decisão de continuar e seu entendimento pode fazer a tosse reduzir de intensidade e frequencia e ser tolerável. O uso inalatório do cromoglicato de sodio Rilan Nasal $4 \% \circledR$ pode ser útil na redução da mesma. ${ }^{8}$

Em pacientes com tosse crônica a Associação América de Médicos do Torax $^{23}$ no seu guia prático baseado em evidências, recomendam que se houver indicação de prescrever IECAs devem tratar a tosse crônica antes e observar, pois pode até não ocorrer piora da mesma. Não existindo contraindicação formal para sua prescrição.

\section{REFERÊNCIAS}

1. Magalhães LBNC, Amorim AM, Rezende EP. Conceito e Aspectos Epidemiológicos da Hipertensão Arterial. Rev Bras Hipert. 2018;25:6-12.

2. Ross SD, Akhras KS, Zhang S, Rozinsky M, Nalysnyk L. Discontinuation of antihypertensive drugs due to adverse events: a systematic review and meta-analysis. Pharmacotherapy. 2001;21(8):940-53.

3. Pereira ANP. Prevalência da tosse em pacientes com hipertensão arterial refratária em uso de Inibidores da Enzima de Conversão da Angiotensina. 2016 - repositorio.ufba.br. Acesso em 1 de outubro de 2020. Disponível em: https://repositorio.ufba.br/ri/handle/ri/21346

4. Malachias MVB, Plavnik FL, Machado CA, Malta D, Scala LCN, Fuchs S. $7^{\text {a }}$ Diretriz Brasileira de Hipertensão. Arq Bras Cardiol. 2016;107(3):1-83.

5. Antonios TFT, Macgregor GA. Angiotensin Converting Enzyme inhibitors in Hypertension: Potencial problem. J Hypert. 1995;13(3): S11-S16.

6. Couter DM, Edwards IR. Cough associated with captopril and enalapril. $\mathrm{Br}$ Med J. 1987; 294:1521-23.

7. Strocchi E, Valtancoli G, Ambrosioni E. The incidence of cough during treatment with angiotensin converting enzyme inhibitors. J Hypert. 1989; 7(6):S308-S309.

8. IsraeliZ, Wall WD. Cough and angioneurotic edema associated with angiotensinconverting enzyme inhibitors. Annals Intern Med. 1992; 117;234-42.

9. RumboldtZ, MarinkovicM, Drinovec J. Enalapril versus captopril: a double-blind multicenter comparison in essential hypertension. Int J Clin Pharmacol Res. 1988;8:181-8.

10. Lacourcière $Y$, Poirier $L$, Provencher $P$, Guivarc' $h$ PH. Once vs twice-daily administration of a fixed combination of captopril plus Hydrochlorothiazide in essencial hypertension: A double-blind crossover study in known responders to a standard combination. Br J Clin Pharmacol. 1991;32(1):115-19.

11. Rossetto BJ. Side effect of captopril and enalapril. West J Med. 1987;146(1):102.

12. Puolijoki H, Nieminen M, Moilanen E, Siitonen L, Lahdensuo A, Reinikainen $P$, et al. Cough induced by enalapril but not by captopril. European Respiratory Journal. 1989;2:289-91.

\section{ASPECTOS PRÁTICOS}

Um interessante artigo de Bagalore et al. ${ }^{24}$ desenhado para comparar a taxa de tosse relatada na literatura com taxas relatadas no Physicians 'Desk Reference (PDR) / etiqueta do medicamento (BULA) os autores pesquisaram no MEDLINE / EMBASE / CENTRAL por artigos publicados de 1990 até 2010 e encontraram uma grande discrepância entre os estudos relatados e a descrição nas respectivas bulas dos diferentes IECAs. A incidência de tosse nas bulas foram muito menores que os estudos realmente apresentaram. Assim neste caso, se guiar por estas informações comerciais não parece ser confiável.

Assim, penso que a tosse não deve ser um impedimento para a prescrição dos IECAs. E nos casos em que a tosse esteja realmente relacionada e incomodativa deve-se suspender e trocar a classe.

13. Morice AH, Brown MJ, Higenbottam LR. Cough associated with Angiotensinconverting enzyme inhibitors. J Cardiovasc. Pharmacology. 1989; 13(3):S59-S62.

14. Town Gl, Hallwright GP, Maling TJ, O'Donnel TV. Angiotensin-converting enzyme inhibitors and cough. N Z Med J. 1987;100(820):161-3.

15. Woo KS, Norris RM, Nicholls G. The Racial Difference in Incidence od cough with Angioten -Converting Enzyme Inhibitors (A tale of Two Cities). Amer Cardiol. 1995; 75:967-68

16

17. Ng LP, Goh PSC. Incidence of discontinuation of angiotensin-converting enzyme inhibitors due to cough, in a primary healthcare centre in Singapore. Singapore Med J. 2014; 55(3):146-49.

18. R Guthrie Fosinopril: an overview. Am J Cardiol. 1993;72(20):PH22-H24.

19. Shari MN, Evans BL, Pylypchuk GB. Cough induced by Quinapril with resolution After Changing to Fosinopril. Ann Pharmacother. 1994; 28:720-2.

20. Brugts JJ, Arima H, Remme W, M Bertrand, R Ferrari, K Fox, et al. The incidence and clinical predictors of ACE-inhibitor induced dry cough by perindopril in 27,492 patients with vascular disease. Int J Cardiol. 2014;176(3):718-23.

21. Poggi L, Renucci JF, Denolle T. Treatment of essential hypertension in general practice: an open-label study of 47,351 French hypertensive patients treated for one year with perindopril. Can J Cardiol. 1994;10:21D-24D.

22. Ogilvie RI, Anand S, Roy P, De Souza S; PEACH investigators. Perindopril for control of blood pressure in patients with hypertension and other cardiovascular risk factors: an open-label, observational, multicentre, general practice-based study. Clin Drug Investig. 2008;28(11):673-86.

23. Dicpinigaitis PV. Angiotensin-converting enzyme inhibitor-induced cough: ACCP evidence-based clinical practice guidelines. Chest. 2006; 129(1):169S-173S.

24. Bangalore S, Kumar S, Messerli FH. Angiotensin-converting enzyme inhibitor associated cough: deceptive information from the Physicians' Desk Reference. Am J Med. 2010;123(11):1016-30. 